\title{
Thermal Behaviour of the mSR Relaxation Rate at High Temperature in Insulators
}

DOI:

10.1007/3-540-30924-1_21

\section{Document Version}

Final published version

Link to publication record in Manchester Research Explorer

\section{Citation for published version (APA):}

Dalmas de Reotier, P., Yaouanc, A., Gubbens, P. C. M., Sakarya, S., Jimenez-Melero, E., Bonville, P., \& Hodges, J. A. (2004). Thermal Behaviour of the mSR Relaxation Rate at High Temperature in Insulators. Hyperfine Interactions, 158, 131-136. https://doi.org/10.1007/3-540-30924-1_21

\section{Published in:}

Hyperfine Interactions

\section{Citing this paper}

Please note that where the full-text provided on Manchester Research Explorer is the Author Accepted Manuscript or Proof version this may differ from the final Published version. If citing, it is advised that you check and use the publisher's definitive version.

\section{General rights}

Copyright and moral rights for the publications made accessible in the Research Explorer are retained by the authors and/or other copyright owners and it is a condition of accessing publications that users recognise and abide by the legal requirements associated with these rights.

\section{Takedown policy}

If you believe that this document breaches copyright please refer to the University of Manchester's Takedown Procedures [http://man.ac.uk/04Y6Bo] or contact uml.scholarlycommunications@manchester.ac.uk providing relevant details, so we can investigate your claim.

\section{OPEN ACCESS}




\title{
Thermal Behaviour of the $\mu$ SR Relaxation Rate at High Temperature in Insulators
}

\author{
P. DALMAS DE RÉOTIER ${ }^{1, *}$, A. YAOUANC ${ }^{1}$, P. C. M. GUBBENS ${ }^{2}$, \\ S. SAKARYA ${ }^{2}$, E. JIMENEZ ${ }^{3}$, P. BONVILLE ${ }^{4}$ and J. A. HODGES ${ }^{4}$ \\ ${ }^{1}$ Commissariat à l'Energie Atomique,DRFMC, Grenoble,France; e-mail: pdalmas@cea.fr \\ ${ }^{2}$ Technische Universiteit Delft, IRI, Delft, The Netherlands \\ ${ }^{3}$ Universidad Complutense de Madrid, Fac. C. Quimicas, Madrid, Spain \\ ${ }^{4}$ Commissariat à l'Energie Atomique, DRECAM, Saclay, France
}

\begin{abstract}
We show that, in rare earth based insulators, measurement of the thermal dependence of the muon spin-lattice relaxation rate at high temperature provides information on the nature of the magnetic correlations and on the crystal-field energy splitting, if any.
\end{abstract}

Key Words: magnetic correlations, $\mu$ SR spin-lattice relaxation, Orbach process.

\section{Introduction}

The spin dynamics in rare earth based insulators at high temperature is expected to be controlled by two physical mechanisms. One is associated with the exchange interaction between the rare earth spins (mutual spin-flips) and the second is due to the magneto-elastic coupling between these spins and the phonons (single spin-flip with absorption/emission of phonons). The muon spin relaxation $(\mu \mathrm{SR})$ technique is a well adapted tool to probe the spin dynamics in a broad temperature range.

We provide here the framework for interpreting $\mu \mathrm{SR}$ data recorded at high temperature, where the thermal energy is bigger than the characteristic exchange energy in the system. As an illustration, we present experimental data that we have recently obtained in geometrically frustrated magnetic systems. Our interpretative framework is not intended to specifically address the issues of geometrical magnetic frustration, which are actually most easily observed at low temperature [8]. It holds for any magnetic insulator well above the magnetic transition temperature, if any.

\footnotetext{
* Author for correspondence.
} 


\section{Theoretical framework for the muon relaxation rate}

We consider the case where the zero-field $\mu$ SR spectra are well accounted for by an exponential relaxation function characterised by a decay (or relaxation) rate $\lambda_{Z}$. When a magnetic compound is cooled down from a temperature high enough so that the thermal energy is large compared to the exchange energy, short-range pair-correlations are expected to progressively build up. They were first detected by nuclear magnetic resonance as an increase (decrease) of the spin-lattice relaxation rate for a ferromagnetic (antiferromagnetic) compound as it is cooled down and the pair correlations become increasingly important [9]. This is qualitatively understood as ferromagnetic (antiferromagnetic) correlations correspond to the enhancement (reduction) of the local field at the nuclear probe.

In the limit $T \rightarrow \infty$, there is no correlation between different spins. At finite temperature, one can expand the static correlation function of the total momentum $J$ of the rare earth $\left\langle\delta J_{i}^{\alpha} \delta J_{j}^{\beta}\right\rangle$ to first order in $\mathcal{J} /\left(k_{\mathrm{B}} T\right)$, where $\mathcal{J}$ is the exchange constant $[3,9]$ :

$$
\left\langle\delta J_{i}^{\alpha} \delta J_{j}^{\beta}\right\rangle=\delta_{\alpha, \beta} \frac{2 \mathcal{J}}{k_{\mathrm{B}} T}\left[\frac{1}{3} J(J+1)\right]^{2} .
$$

A cubic compound is assumed for simplicity. A key feature is evident from this formula: the pair-correlation depends on the sign of $\mathcal{J}$, being positive (negative) for ferromagnetic (antiferromagnetic) exchange. Taking into account the short-range correlations to first order in $\mathcal{J} /\left(k_{\mathrm{B}} T\right), \lambda_{Z}$ can be written [3]:

$$
\lambda_{Z}(T)=\lambda_{Z}^{(\mathrm{ss})}\left(1+\frac{T_{0}}{T}\right)
$$

where $\lambda_{z}^{(\mathrm{ss})}$ is the value of the muon spin-lattice relaxation rate in the high temperature limit, where cross-correlations vanish, and $T_{0}$ is a characteristic temperature, the sign and order of magnitude of which are those of the paramagnetic Curie-Weiss temperature $\theta_{\mathrm{CW}}$. The absolute value of $\theta_{\mathrm{CW}}$ is proportional to the exchange constant $\mathcal{J}$, its sign is positive for ferromagnets and negative for antiferromagnets. It must be emphasized that $\left|T_{0}\right|$ is not only a function of the pair-correlation, but that it depends drastically on the rare earth spin configuration around the muon, and that it may even vanish. To illustrate this point, let us assume that the muon interacts only with near neighbour spins. If there is only one such spin nearby the muon, pair correlations cannot influence the muon spin and $T_{0}=0$. On the other hand, if two magnetic ions interact with the muon spin, $T_{0} \neq 0$.

In addition to exchange driven spin relaxation, an additional mechanism can be operative in rare earth systems with well-defined crystal-field energy 
levels: the Orbach process, a two-phonon real process via an excited crystal-field level $[2,7]$. The associated inverse muon relaxation rate is:

$$
\lambda_{Z}^{-1}=B_{m} \exp \left(\frac{-\Delta_{e}}{k_{\mathrm{B}} T}\right),
$$

where $B_{m}$ is a magnetoelastic coupling constant of the ionic spin with the phonon bath.

Combining the exchange and phonon driven relaxation mechanisms, we expect the inverse muon relaxation rate $\lambda_{Z}^{-1}$ for an insulator to be given by the expression:

$$
\lambda_{Z}^{-1}=\left[\lambda_{Z}^{(\mathrm{ss})}\left(1+\frac{T_{0}}{T}\right)\right]^{-1}+B_{m} \exp \left(\frac{-\Delta_{e}}{k_{\mathrm{B}} T}\right) .
$$

\section{The spin-lattice relaxation rate data}

We now present experimental results obtained in four geometrically frustrated systems: $\mathrm{Gd}_{2} \mathrm{Ti}_{2} \mathrm{O}_{7}, \mathrm{Gd}_{2} \mathrm{Sn}_{2} \mathrm{O}_{7}, \mathrm{Yb}_{2} \mathrm{Ti}_{2} \mathrm{O}_{7}$ and $\mathrm{Yb}_{3} \mathrm{Ga}_{5} \mathrm{O}_{12}$. The data have been recorded at the Swiss Muon Source and at the ISIS muon facility in UK.

$\theta_{\mathrm{CW}}$ for $\mathrm{Gd}_{2} \mathrm{Ti}_{2} \mathrm{O}_{7}, \mathrm{Gd}_{2} \mathrm{Sn}_{2} \mathrm{O}_{7}$ and $\mathrm{Yb}_{2} \mathrm{Ti}_{2} \mathrm{O}_{7}$ are, respectively, -9.9 (1) $\mathrm{K}$, -8.6 (1) $\mathrm{K}$ [1] and $0.75 \mathrm{~K}$ [5]. That for $\mathrm{Yb}_{3} \mathrm{Ga}_{5} \mathrm{O}_{12}$ is very small and consequently its sign is difficult to determine. However, at low temperature, the susceptibility deviates from the Curie-Weiss behaviour extrapolated from high temperature in such a way that the presence of antiferromagnetic interactions is suggested [2]. Both $\mathrm{Gd}_{2} \mathrm{Ti}_{2} \mathrm{O}_{7}$ and $\mathrm{Gd}_{2} \mathrm{Sn}_{2} \mathrm{O}_{7}$ display an antiferromagnetic phase transition at about $1 \mathrm{~K}$ [1]. The $\mathrm{Yb}$-based compounds are characterised by a specific heat anomaly at low temperature $(0.25$ and $0.054 \mathrm{~K}$ for $\mathrm{Yb}_{2} \mathrm{Ti}_{2} \mathrm{O}_{7}$ and $\mathrm{Yb}_{3} \mathrm{Ga}_{5} \mathrm{O}_{12}$, respectively) but do not show long range magnetic order $[2,5]$.

Figures 1 and 2 show the thermal dependence of $\lambda_{Z}$ together with fits to Equation (4). Our model, which describes the onset of pair correlations, is derived from an expansion of the correlation function with respect to the ratio of the exchange and thermal energies. It is therefore expected to break down when the temperature is low enough $\left(k_{\mathrm{B}} T \sim \mathcal{J}\right)$, where critical dynamics prevails. The fits to Equation (4) were therefore performed in the temperature range above $\sim 10 \mathrm{~K}$, except for $\mathrm{Yb}_{3} \mathrm{Ga}_{5} \mathrm{O}_{12}$ (above $0.3 \mathrm{~K}$ ). Table I gathers the values obtained for the various parameters.

For $\mathrm{Gd}_{2} \mathrm{Ti}_{2} \mathrm{O}_{7}$ and $\mathrm{Gd}_{2} \mathrm{Sn}_{2} \mathrm{O}_{7}$, no Orbach process was included in the fit $\left(B_{m}=0\right)$ because the $\mathrm{Gd}^{3+}$ ion has a vanishingly small crystal field splitting. The antiferromagnetic nature of the exchange interaction in these compounds is seen in the slight decrease of $\lambda_{Z}(T)$ on cooling. The corresponding $T_{0}$ values are therefore negative. Below $10 \mathrm{~K}, \lambda_{Z}$ increases as the critical regime is approached. 


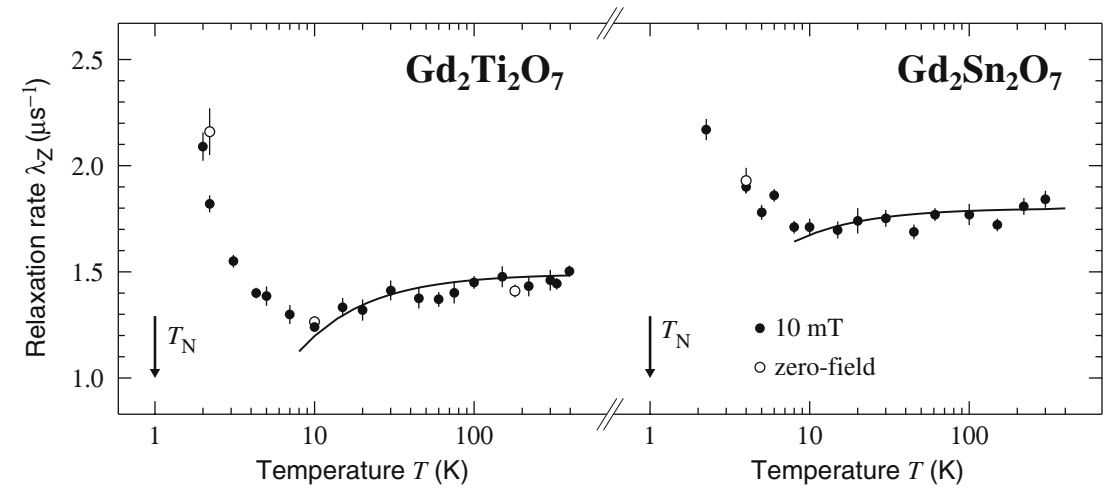

Figure 1. Relaxation rate $\lambda_{Z}$ measured in $\mathrm{Gd}_{2} \mathrm{Ti}_{2} \mathrm{O}_{7}$ and $\mathrm{Gd}_{2} \mathrm{Sn}_{2} \mathrm{O}_{7}$ using zero- or longitudinalfield $\mu \mathrm{SR}$. To emphasize the slight temperature dependence observed deep in the paramagnetic phase we show only data for $T \geq 2 \mathrm{~K}$. Below $2 \mathrm{~K}, \lambda_{Z}$ continues to rise to reach a maximum at $T_{\mathrm{N}}$ [10] as expected when approaching a phase transition. The lines are fits to Equation (4). They point to the presence of antiferromagnetic pair correlations.
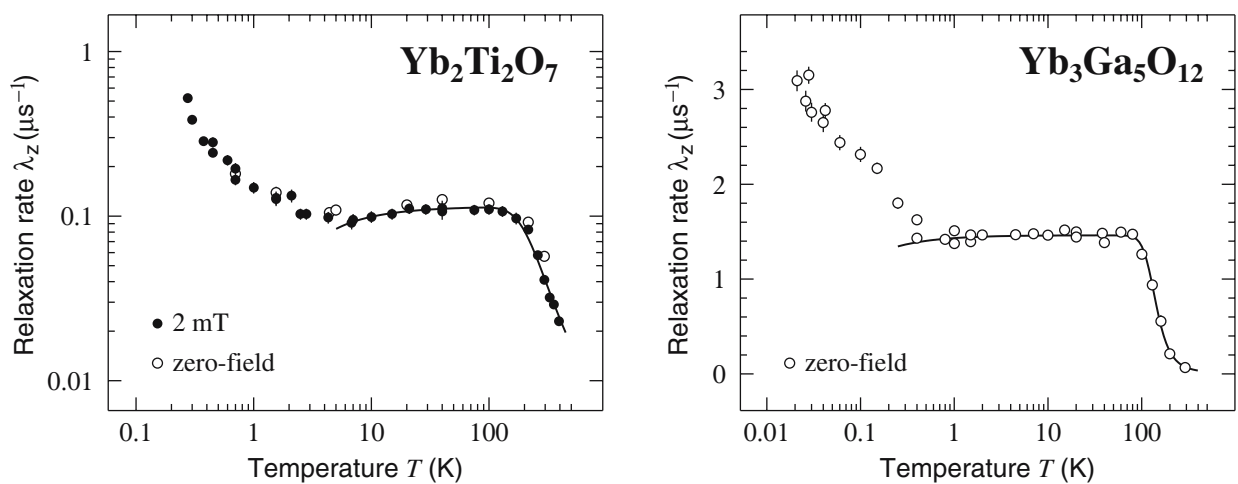

Figure 2. Relaxation rate $\lambda_{Z}$ measured in $\mathrm{Yb}_{2} \mathrm{Ti}_{2} \mathrm{O}_{7}$ and $\mathrm{Yb}_{3} \mathrm{Ga}_{5} \mathrm{O}_{12}$ using zero- or longitudinalfield $\mu \mathrm{SR}$. The lines are fits to Equation (4). Above $\sim 100 \mathrm{~K}$, they reflect the presence of crystalfield levels and at lower temperature the onset of antiferromagnetic correlations. In the case of $\mathrm{Yb}_{2} \mathrm{Ti}_{2} \mathrm{O}_{7}$, only the $2 \mathrm{mT}$ data have been used for the fit.

Table I. Parameters obtained from the fits shown in Figures 1 and 2.

\begin{tabular}{lllll}
\hline Compound & $T_{0}(\mathrm{~K})$ & $\lambda_{\mathrm{Z}}^{(\mathrm{ss})}\left(\mu \mathrm{s}^{-1}\right)$ & $\Delta_{e} / k_{\mathrm{B}}(\mathrm{K})$ & $B_{m}(\mu \mathrm{s})$ \\
\hline $\mathrm{Gd}_{2} \mathrm{Ti}_{2} \mathrm{O}_{7}$ & $-2.0(2)$ & $1.49(3)$ & - & - \\
$\mathrm{Gd}_{2} \mathrm{Sn}_{2} \mathrm{O}_{7}$ & $-0.7(2)$ & $1.80(5)$ & - & - \\
$\mathrm{Yb}_{2} \mathrm{Ti}_{2} \mathrm{O}_{7}$ & $-1.4(2)$ & $0.115(2)$ & $900(50)$ & $310(80)$ \\
$\mathrm{Yb}_{3} \mathrm{Ga}_{5} \mathrm{O}_{12}$ & $-0.02(1)$ & $1.46(5)$ & $825(15)$ & $215(20)$
\end{tabular}

The absence of crystal field splitting in the Gd compounds implies that relaxation by the Orbach process is ineffective $\left(B_{m}=0\right.$ in Equation (4)). 
In $\mathrm{Yb}_{2} \mathrm{Ti}_{2} \mathrm{O}_{7}$ and $\mathrm{Yb}_{3} \mathrm{Ga}_{5} \mathrm{O}_{12}, \lambda_{Z}(T)$ also points to antiferromagnetic interactions. As expected from macroscopic measurements, $T_{0}$ is found to be close to 0 in the latter compound. As to $\mathrm{Yb}_{2} \mathrm{Ti}_{2} \mathrm{O}_{7}$, the results are surprising. The sign found for $T_{0}$ is opposite to that of $\theta_{\mathrm{CW}}$. An explanation for this discrepancy could arise from the (unknown) muon localisation site. This site could be such that only specific pair correlations are probed by $\mu \mathrm{SR}$, whereas $\theta_{\mathrm{CW}}$, derived from the macroscopic susceptibility, is sensitive to the sum of the exchange interactions. We recall at this point that frustrated systems are essentially characterised by competing exchange interactions.

Turning now to phonon induced relaxation, the fits give for the relevant crystal field energies: $\Delta_{e} / k_{\mathrm{B}}=900$ (50) and 825 (15) $\mathrm{K}$ for $\mathrm{Yb}_{2} \mathrm{Ti}_{2} \mathrm{O}_{7}$ and $\mathrm{Yb}_{3} \mathrm{Ga}_{5} \mathrm{O}_{12}$ respectively. The combination of results obtained from ${ }^{170} \mathrm{Yb}$ Mössbauer spectroscopy, ${ }^{172} \mathrm{Yb}$ perturbed angular correlation, magnetisation and susceptibility measurement has allowed to establish the crystal-field level scheme of $\mathrm{Yb}^{3+}$ in $\mathrm{Yb}_{2} \mathrm{Ti}_{2} \mathrm{O}_{7}$. It consists of three doublets located at 620,740 and $950 \mathrm{~K}$ above the ground state doublet [4]. Using a similar procedure, it was determined that the three excited doublets of $\mathrm{Yb}^{3+}$ in $\mathrm{Yb}_{3} \mathrm{Ga}_{5} \mathrm{O}_{12}$ are closely spaced and lie at an average energy corresponding to $850 \mathrm{~K}$ above the ground state [6]. The values found for $\Delta_{e} / k_{\mathrm{B}}$ in the two $\mathrm{Yb}$ compounds compare therefore very well with the known crystal field levels. Consequently we conclude that the marked drop observed in $\lambda_{Z}$ above $\sim 100 \mathrm{~K}$ is the signature of a muon spin relaxation associated with a two-phonon real process through the excited crystal field states (Orbach process).

In conclusion, we have shown that, for the magnetic insulators of interest here, two physical mechanisms allow to interpret the thermal dependence of the $\mu \mathrm{SR}$ relaxation rate in a high temperature regime compared to the exchange energy. First, the building up of spin pair correlations is characterised by an increase (decrease) of $\lambda_{Z}$ when lowering the temperature in the case of ferromagnetic (antiferromagnetic) interactions. The nature of the pair correlations which are probed by the muon, e.g. between nearest neighbours or next nearest neighbours, depends on the muon localisation site. Second, the presence of crystal field levels induces a marked temperature dependence of $\lambda_{Z}$ at high temperature.

\section{References}

1. Bonville P., Hodges J. A., Sanchez J. P., Vulliet P., Sosin S. and Braithwaite D., J. Phys. Condens. Matter. 15 (2003), 7777.

2. Dalmas de Réotier P., Yaouanc A., Gubbens P. C. M., Kaiser C. T., Baines C. and King P. J. C., Phys. Rev. Lett. 91 (2003), 167201.

3. Hartmann O., Karlsson E., Wappling R., Chappert J., Asch A. Y. L. and Kalvius G. M., J. Phys. F. Metal Phys. 16 (1986), 1593.

4. Hodges J. A., Bonville P., Forget A., Rams M., Królas K. and Dhalenne G., J. Phys. Condens. Matter. 13 (2001), 9301. 
5. Hodges J. A., Bonville P., Forget A., Yaouanc A., Dalmas de Réotier P., André A., Rams M., Królas K., Ritter C., Gubbens P. C. M., Kaiser C. T., King P. J. C. and Baines C., Phys. Rev. Lett. 88 (2002), 077204.

6. Hodges J. A, Bonville P., Rams M. and Królas K., J. Phys. Condens. Matter. 15 (2001), 4631.

7. Orbach R., Proc. Phys. Soc. Lond. Sect. A 264 (1961), 458.

8. Ramirez A. P., In: Buschow K. H. J. (ed.), Handbook of Magnetic Materials, Vol 13, Elsevier, 2001.

9. Silbernagel B. G., Jaccarino V., Pincus P. and Wernick J. H., Phys. Rev. Lett. 20 (1968), 1091.

10. Yaouanc A., Dalmas de Réotier P., Bonville P., Hodges J. A., Gubbens P. C. M., Kaiser C. and Sakarya S., Physica. B 326 (2003), 456. 